\title{
The "Chemical Imbalance" Explanation for Depression: Origins, Lay Endorsement, and Clinical Implications
}

\author{
Christopher M. France \\ Cleveland State University
}

\author{
Paul H. Lysaker \\ Roudebush Veterans Affairs Medical Center, Indianapolis, and \\ Indiana University School of Medicine
}

\author{
Ryan P. Robinson \\ University of Akron
}

\begin{abstract}
When a client asks whether her or his depression is caused by a chemical imbalance, how do you respond? Depression is regularly depicted in popular media as resulting from a "chemical imbalance" and this depiction raises a number of interesting questions for practicing clinicians. How accurate is the chemical imbalance explanation for depression? How widely do laypersons agree with the explanation, and how do they interpret the explanation? We discuss the origins, accuracy, and transmittal (e.g., via direct-to-consumer advertising) of the chemical imbalance explanation for depression. We next present results from a group case study examining lay endorsement and interpretation of the explanation. Finally, we discuss clinical implications and present a short script for educating clients concerning "chemical imbalances" in depression.
\end{abstract}

Keywords: chemical imbalance, depression, laypersons, direct-to-consumer advertising, monoamines

It is common in the United States for depression to be described as resulting from a "chemical imbalance" (e.g., Valenstein, 1998). As the potentially dominant cultural story of depression etiology, the chemical imbalance explanation may exert a significant effect on treatment-seeking behaviors as well as the structures that are created and maintained for such treatment (e.g., Smith, 1999; also see Rothman, 1971). As such, it appears important for mental health professionals and other stakeholders (e.g., policymakers) to understand lay beliefs concerning chemical imbalance explanations for depression.

CHRISTOPHER M. FranCE received his PsyD in clinical psychology from Wright State University. He is an assistant psychology professor at Cleveland State University and a licensed psychologist. His research interests include cultural and personal conceptions of mental disorders and their treatment.

PAUl H. LySAKER received his $\mathrm{PhD}$ in clinical psychology from Kent State University. He is a staff clinical psychologist at the Roudebush Veterans Affairs Medical Center, Day Hospital 116H, and an assistant clinical professor of psychology at the Indiana University School of Medicine, Department of Psychiatry. His major areas of interest include vocational rehabilitation, personal narratives, and recovery from severe mental illness. RYAN P. ROBINSON received his MA in industrial organizational psychology from the University of Akron, where he is also a doctoral candidate in industrial organizational psychology. $\mathrm{He}$ is also a part-time lecturer at Cleveland State University. His areas of interest include employee training and development, affective reactions in the workplace, and research methods and statistics.

WE THANK Heather Dukes for assisting with background research and data organization.

CORRESPONDENCE CONCERNING THIS ARTICLE should be addressed to Christopher M. France, Department of Psychology, Cleveland State University, Chester Building 159, 2121 Euclid Avenue, Cleveland, OH 44115. E-mail: c.m.france@csuohio.edu
We do not dispute the possibility that neurotransmitters and other brain chemicals play a significant role in the etiology of depression. However, we are also concerned that the chemical imbalance explanation may not reflect the full range of causes of depression, may be given greater credence by both consumers and practitioners than is supported by sound research, and/or may be understood in an overly simplistic manner. Any unitary understanding of human suffering asserted in isolation of its nuances may mislead those in need of treatment and confound selfunderstanding, resulting in treatment-seeking strategies and outcomes that are less than optimal for at least some clients.

\section{The Development of Chemical Imbalance Explanations for Depression}

Modern chemical imbalance hypotheses of depression originated in the mid-20th century, spurred by important discoveries such as the efficacy of chlorpromazine for psychosis; findings that monoamines exist within the central nervous system (CNS) and act as neurotransmitters; and an early understanding of monoamine synthesis, storage, release, and deactivation. Such discoveries also quickened the emergence of psychopharmacology as a discipline and helped lead to the eventual widespread practice of using prescription drugs to treat mental disorders also (e.g., Healy, 2001).

\section{Iproniazid and Imipramine}

The 1950s saw the appearance of the first antidepressant drugs of the modern era, two being iproniazid and imipramine (Healy, 1997). Iproniazid's initial importance was as an effective tuberculosis treatment, but it was also noted that some tubercular patients 
taking the drug experienced psychostimulation and euphoria. Following such observations, the drug was tested on a variety of psychiatric patients in and outside the United States (Baumeister, Hawkins, \& Uzelac, 2003; Crane, 1957). In one early study, iproniazid was given to 17 institutionalized female patients who were "withdrawn, regressed, ... and of flattened affect" (Loomer, Saunders, \& Kline, 1957, p. 133). Of the 17 patients, $70 \%$ "showed at least some favorable response" (p. 137) after 5 months of iproniazid treatment. The same authors also reported the successful use of iproniazid with a small sample of depressed outpatients (Loomer et al., 1957). Such results were widely publicized, and iproniazid became (for several years, until its withdrawal from the market because of potentially serious side effects) a popular treatment for depression (Healy, 2001).

Imipramine resulted from a conscious attempt to replicate the success of chlorpromazine, the first widely used antipsychotic drug. Chemists at Geigy derived a number of drugs (including imipramine) from iminodibenzyl, a compound with a (tricyclic) central molecular structure resembling that of chlorpromazine (Healy, 1997). Imipramine was found ineffective as a neuroleptic in one early, large-scale study; however, a later review of nursing notes suggested some patients had experienced elevated moods during the trial (Healy, 2001). This observation justified a trial of imipramine with a sample of about 40 depressed (rather than psychotic) patients. Roland Kuhn (1958), a psychiatrist who was involved in the above studies and who also used imipramine extensively in the clinical setting, concluded that imipramine was quite effective as a treatment for depression. Imipramine was marketed in the United States beginning in 1958 (Healy, 2001).

\section{Reserpine's Role}

The 1950s also saw investigations of the properties of reserpine, an alkaloid derived from the root of Rauwolfia serpentina. The root caught the attention of U.S. researchers because of its use in India as an herbal treatment for hypertension and psychosis (Healy, 1997). Reserpine was initially marketed in the United States as a sedative and antihypertensive drug (Baumeister et al., 2003), with Nathan Kline (e.g., Barsa \& Kline, 1956) being among the first in the United States to document its effects on psychiatric symptoms. Reserpine was found to have clear sedating as well as moderate neuroleptic effects. Though used rather frequently as a neuroleptic in the 1950s, reserpine never achieved chlorpromazine's popularity and is rarely used today as a neuroleptic.

Reserpine did, however, play a significant role in the development of chemical imbalance theories of depression. Serotonin had been found in animal studies (e.g., Bogdanski, Weissbach, \& Udenfriend, 1958) to exist in the CNS and to have activating effects on behavior. Reserpine was found to deplete brain serotonin stores, and it was hypothesized that reserpine's characteristic (depressive-like) effects of sedation and lethargy were due to such serotonin depletion (e.g., Shore, Silver, \& Brodie, 1955). Reserpine also acquired a reputation (in retrospect likely undeserved) as depressogenic for humans after it was reported in multiple papers (see Baumeister et al., 2003, for a review) that patients taking the drug for hypertension tended to develop depressive symptoms.

Previous research focused on the inactivation of adrenaline led to the discovery of an enzyme, now known as monoamine oxidase (MAO), that oxidized not only adrenaline, but also the mono- amines noradrenaline, dopamine, and serotonin (Healy, 1997). Some effective tuberculosis drugs were known to inhibit MAO's effects, and iproniazid (the tuberculosis drug turned antidepressant) was found to be a potent MAO inhibitor (MAOI). Importantly, iproniazid was further found to block the behavioral effects of reserpine, presumably by slowing the oxidation of serotonin depleted from presynaptic stores via reserpine. In turn, this would allow more serotonin to reach and be released at neural synapses.

It is at this point-that is, where serotonin depletion via reserpine leads to depression, and where such symptoms are thought to be blocked by the (serotonin-enhancing MAOI) antidepressant iproniazid - that a serotonin deficit hypothesis of depression becomes possible. Reserpine was later found to also deplete the catecholamines, making it possible (as the MAOIs such as iproniazid also inhibit catecholamine oxidation) to expand a potential serotonin deficit model of depression to include the catecholamines. Such monoamine deficiency theories were buttressed by later findings that imipramine also increased the synaptic availability of certain monoamines (primarily serotonin and norepinephrine) by blocking their uptake into presynaptic terminal buttons (Glowinski \& Axelrod, 1964; also see Pletscher, 1991).

Though previous authors (e.g., see Brodie \& Shore, 1957) had speculated that low monoamine levels could cause depressive states and that increasing monoamines might reduce depression, Schildkraut (1965) is often credited with the first clear statement of the catecholamine hypothesis of depression, and Coppen (1967) is often credited with developing the serotonin hypothesis of depression. Regardless of how credit is allocated, such "imbalance" theories (i.e., the monoamine hypothesis) have played a dominant role for the past 40 years or so in guiding research aimed at understanding the biological bases of depression and developing pharmacological treatments for the same (e.g., Hindmarch, 2002).

\section{How Accurate Are Chemical Imbalance Explanations of Depression?}

\section{Response to and Efficacy of Antidepressants}

Multiple findings (e.g., Masand \& Gupta, 1999; Kessler et al., 2003) that antidepressants (which typically increase monoamine levels) reduce depressive symptoms have been seen as abundant support for the chemical imbalance explanation of depression. However, response to antidepressants is not by itself proof that an imbalance of brain chemicals causes depression. Psychotherapy can alleviate depression (e.g., Antonuccio, Danton, DeNelsky, Greenberg, \& Gordon, 1999); therefore (using the above logic), a deficiency of psychotherapy causes depression (of course, we are unaware of any serious assertions to this effect).

Also interfering with response-equals-causation logic are findings that in many clinical trials, antidepressants have exhibited either no or very modest advantages in comparison with placebos (Kirsch, Moore, Scoboria, \& Nicholls, 2002; Kirsch, Scoboria, \& Moore, 2002). Such findings raise the possibility that antidepressants may often act as active placebos rather than having unique and specific antidepressant properties. As well, note that monoamine enhancers are not the only drugs found effective for depression; for example, tianeptine is an effective antidepressant (Wagstaff, Ormrod, \& Spencer, 2001) that lowers serotonin levels in the brain by enhancing rather than slowing presynaptic serotonin uptake. 
The above studies do not directly test chemical imbalance explanations of depression but do provide information relevant to the accuracy of such claims. If depression can be reduced via multiple means such as medication, placebo responses, psychotherapy, exercise (e.g., Babyak et al., 2000), and so forth, then perhaps depression is multicausal and multifactorial in nature rather than resulting solely or primarily from an imbalance of brain chemicals. If so, it would appear appropriate for clinicians to educate their patients as to such multiple causes of, and multiple effective treatments for, depression.

\section{Measurements of Monoamines and Their Metabolites in Depression}

Consistent findings of low monoamine levels in depressed persons might also be looked to as support for chemical imbalance theories of depression etiology. Monoamines and/or their metabolites can be measured within the cerebrospinal fluid (CSF), blood plasma and platelets, urine, extracellular brain fluid, or postmortem brain slices (e.g., see Gjerris, 1988). Direct brain measurements of monoamines are typically accomplished by using animals (e.g., Bianchi, Moser, Lazzarini, Vecchiato, \& Crespi, 2002) or postmortem brains (either human or animal). A primary metabolite of serotonin is 5-hydroxyindoleacetic acid (5-HIAA), and 3-methoxy-4-hydroxyphenylglycol (MHPG) is a major norepinephrine metabolite (Delgado, 2000).

Lowered monoamine/metabolite levels have indeed been found in some depressed groups. For example, Asberg, Thoren, Traskman, Bertilsson, and Ringberger (1976) found levels of CSF 5-HIAA correlated with severity of depression in some depressed patients. Sedvall et al. (1980) found lowered CSF 5-HIAA levels in normal controls with a family history of depression and suggested CSF 5-HIAA levels might act as a marker of genetic vulnerability for depression. Asberg et al. (1984) found lowered levels of CSF 5-HIAA in patients with melancholia in comparison with nondepressed controls.

However, such findings have been far from consistent. In multiple studies conducted in the 1960s through the 1980s (see Gjerris, 1988, for a review), there was little evidence that monoamine levels could be reliably linked to depression. Recent studies focusing primarily on serotonin and norepinephrine have often found normal levels (i.e., similar to those seen in nondepressed controls) of such transmitters and their metabolites in depressed persons (e.g., see Delgado, 2000). A logical conclusion from the above findings is that some depressed persons may exhibit lowered monoamine levels whereas others do not. Furthermore, the existence of positive findings does not establish a temporal or causal relationship; that is, the lowered monoamine levels found in some studies may be a result rather than a cause of depression or may simply reflect a correlation that is not particularly meaningful with respect to depression etiology.

\section{Monoamine Depletion Studies}

Monoamine depletion studies appear to most directly test chemical imbalance hypotheses of depression. Here, CNS monoamine levels are transiently reduced and then restored, and the effects of such changes on mood are measured. Serotonin is depleted via short-term dietary restrictions and administration of a tryptophan- free amino acid drink; these methods prevent the synthesis of serotonin by depleting its precursor, tryptophan (Delgado, 2000, 2004). Norepinephrine and dopamine production are reversibly inhibited via the administration of alpha-methyl-para-tyrosine (AMPT; see Delgado, 2000, for details).

In a number of studies, some but not all patients in remission from depression via antidepressants have experienced a transient return of symptoms during monoamine depletions (e.g., Delgado et al., 1990, 1993; Miller, Delgado, Salomon, Berman, et al., 1996). A consistent finding has been that participants in remission via selective serotonin reuptake inhibitors (SSRIs) - these boost serotonin levels-are more likely to experience a return of symptoms when serotonin is depleted (e.g., Delgado et al., 1999; Delgado \& Moreno, 1999; Salomon, Miller, Delgado, \& Charney, 1993). Conversely, those in remission via norepinephrine reuptake inhibitors are more likely to experience a return of symptoms during (AMPT-induced) reductions of norepinephrine (e.g., Delgado, 2000). Monoamine depletion has also been found to induce transient depressive symptoms in about $60 \%$ of remitted, (now) medication-free subjects (Neumeister et al., 2004) as well as some healthy subjects with a strong family (but no personal) history of affective illness (Benkelfat, Ellenbogen, Dean, Palmour, \& Young, 1994; Klaassen et al., 1999).

However, a number of findings from monoamine depletion studies contradict a simplistic or universal chemical imbalance theory of depression. First, even when type of monoamine depletion is matched to antidepressant response (e.g., serotonin depletion in SSRI responders), fairly high numbers of subjects experience either no or only mild exacerbation of symptoms (e.g., see Booij et al., 2002). Next, monoamine depletion does not typically exacerbate symptoms in medication-free depressed patients (e.g., Delgado, 2000). An important finding is that monoamine depletion does not typically induce depressive symptoms in healthy subjects without a history of depression (Booij et al., 2002; Delgado \& Moreno, 1999), even in cases where both serotonin and norepinephrine are simultaneously depleted (Salomon, Miller, Krystal, Heninger, \& Charney, 1997). Monoamine depletion studies have been important in suggesting serotonin and norepinephrine play a role in depression and antidepressant response for at least some patients; furthermore, such research might lead to biological markers predicting vulnerability to depression and/or specific antidepressant response (e.g., Berman et al., 1999; Booij et al., 2002) However, as stated succinctly by Miller, Delgado, Salomon, Heninger, and Charney (1996), "monoamine deficiency by itself is insufficient explanation of the cause of depression" (p. 151).

\section{So Where Do We Stand Today?}

In sum, the pathophysiology of depression remains poorly understood (Hindmarch, 2001; Hirschfeld, 2000), and a simplistic chemical imbalance explanation for depression likely lacks adequate validity (Hindmarch, 2002). Monoamine deficiencies continue to be mentioned by some researchers as a potential cause of depression (e.g., Bianchi et al., 2002), but others have declared simply that the monoamine hypothesis "is incorrect" (Owens, 2004 , p. 6). Researchers have increasingly turned toward investigations of other potential biological causes of depression (e.g., Hindmarch, 2001; Leonard, 2000; McEwen, 1999). Related efforts to identify distinct brain changes before, during, and after depres- 
sion treatment are also ongoing (e.g., Cook et al., 2005; Sheline, 2003). However, there are currently no widely available anatomical, chemical, or other biological tests that reliably distinguish the brains of depressed persons from nondepressed persons (e.g., Antonuccio et al., 1999). Multiple etiological models (including biological, environmental, and interactional) of depression remain viable at present.

\section{The Chemical Imbalance Explanation as Cultural Narrative}

Despite its flaws, the chemical imbalance explanation remains the potentially dominant cultural story of depression etiology in the United States (e.g., Smith, 1999). However, cultural narratives of mental illness do not necessarily reflect an objective reality or universal understanding. Different historical and cultural traditions frame depressive experiences within different contexts, thereby promoting and/or limiting particular symptoms and shaping different understandings and meanings of depression and its appropriate treatment. Such narratives are probably best conceptualized as social constructions that must be understood within the cultural context that socializes, interprets, and responds to them (Marsella \& Kaplan, 2002).

One goal of our study was to begin to develop data concerning U.S. laypersons' endorsement and interpretation of the chemical imbalance explanation for depression. We hypothesized in part that U.S. laypersons would report high levels of exposure to and endorsement of chemical imbalance explanations for depression. These hypotheses were based on certain practices, relatively unique to the United States, that might lead U.S. cultural narratives of depression etiology and treatment to differ from those seen in many other countries of the world.

\section{Direct-to-Consumer Advertising as an Influence on Cultural Narratives of Depression}

To elaborate, note that the United States is one of only two developed nations (New Zealand being the other) that explicitly allow direct-to-consumer (DTC) advertising of prescription drugs (Grow, Park, \& Han, 2006). Such advertising is transmitted via a variety of means, such as broadcast and print advertisements, manufacturers' Web sites, and even promotional products emblazoned with a drug's name. There is considerable evidence that U.S. laypersons are regularly exposed to and respond to DTC campaigns touting prescription medications for a variety of conditions (e.g., Antonuccio, Danton, \& McClanahan, 2003). Pharmaceutical companies have exponentially increased spending on DTC advertising over the past 15 years, going from expenditures of roughly $\$ 12$ million in 1989 (Palumbo \& Mullins, 2002) to well over \$3 billion in 2003 (Kravitz et al., 2005). The potential benefits (e.g., educating consumers, increasing help-seeking behaviors) and pitfalls (e.g., the potential overuse of unnecessary medications) of such DTC advertising have been discussed extensively in the literature (e.g., Gardner, Mintzes, \& Ostry, 2003; Sullivan, 2000).

Pharmaceutical companies actively market depression to the U.S. public as a chemical imbalance that antidepressants are able to fix (e.g., Grow et al., 2006). Such efforts are intense, attributable at least in part to the large revenues that can result from antidepressant sales. The United States is the world's largest market for antidepressants (accounting for at least $70 \%$ of worldwide antidepressant sales), and U.S. consumers spent over $\$ 12.5$ billion on antidepressant drugs in 2001 (National Institute for Health Care Management, 2002).

\section{History of DTC Advertising in the United States}

Prescription drug advertising in the United States was limited almost entirely to physicians until about 1981, when some print advertisements targeted toward consumers began to appear (Palumbo \& Mullins, 2002). This development prompted the U.S. Food and Drug Administration (FDA) to request a voluntary moratorium on such ads so that it could consider the implications of the same. In 1985, the FDA clarified that existing regulations governing prescription drug advertising provided adequate safeguards and thus did not need to be changed for advertisements targeted at consumers. The regulations required the inclusion of large amounts of information within the ads (see Palumbo \& Mullins, 2002, for a detailed discussion of the "brief summary," "fair balance," and related provisions), but this could be accomplished without excess difficulty by using one or two pages of print. Print advertisements of prescription medications targeted at consumers thus expanded rapidly beginning in the mid-1980s (Grow et al., 2006).

Television advertising of prescription drugs was not easily accomplished in the 1980s and early 1990s because the amount of information required for DTC ads did not fit easily within a 30-second television commercial (Palumbo \& Mullins, 2002). However, in 1997 (in draft form) and 1999 (in final form) the FDA released guidance statements concerning acceptable consumerdirected broadcast ads for prescription drugs. The guidelines stated that DTC broadcast ads must include a "major statement" of risks and make "adequate provisions" for consumers to obtain the FDA-approved product labeling information for the specific drug. The major statement provision can be met by disclosing the product's major risks in the audio or visual portion of the advertisement. The adequate provision requirement can be met by including several mechanisms (a toll-free telephone number, Web page address, and existing print advertisement) whereby a consumer can access the product labeling information and a statement within the ad that health care providers may provide additional information. The above guidelines made DTC broadcast advertising much more feasible and (quickly) much more common in the United States beginning in the late 1990s.

Today, three broad categories of DTC advertising of prescription drugs are common. "Reminder advertisements" call attention to a drug's name (e.g., on a promotional pen) but do not provide indications for use or other (e.g., dosage) information. "Helpseeking" or "disease-oriented" ads describe the symptoms of a condition and encourage consumers to discuss treatment options with a physician but do not mention a specific drug name. "Product-claim" or "indication" ads do provide a drug's name and its indications and thus must satisfy the brief summary, fair balance, major statement, and adequate provision requirements for print and broadcast ads as described in part above and more fully by Palumbo and Mullins (2002).

DTC advertising is ubiquitous today within the United States (Kravitz et al., 2005). The characterization of depression in such ads as resulting from chemical imbalances has remained relatively 
consistent (e.g., see Lilly, 2006), even as the monoamine hypothesis falls increasingly out of favor. We are interested in how U.S. laypersons receive, interpret, and respond to such DTC messages; as well, we are interested in lay views of depression etiology in countries where such messages are not commonly seen in popular media.

\section{Lay Beliefs (in the United States and Abroad) Concerning the Etiology of Depression}

It is unclear whether U.S. lay views concerning depression etiology have changed significantly over the past $5-10$ years as a result of increases in DTC broadcast ads. Just prior to this phenomenon, there was some evidence that U.S. laypersons did indeed view chemical imbalances as one important cause of depression. Link, Phelan, Bresnahan, Stueve, and Pescosolido (1999; but note that the data were collected in 1996) presented vignettes of depressed persons to a representative sample of U.S. adults and found that a majority $(72.8 \%)$ felt it "somewhat likely" or "very likely" that a "chemical imbalance in the brain" might have caused the depression. However, psychosocial factors were also cited frequently as potential causes of depression, leaving Link et al. to conclude that respondents tended to endorse a "multifactored explanation ... not unlike the diathesis-stress perspective adopted by many mental health experts" (p. 1332). This study is the only one we could find that used both a representative sample and specifically asked about chemical imbalances as a cause of depression.

In contrast to Link et al.'s (1999) findings and subsequent assertions that the chemical imbalance narrative is dominant in the United States, laypersons outside the United States have not yet been found to strongly endorse chemical imbalances as a likely cause of depression. For example, in studies conducted in Switzerland (Lauber, Falcato, Nordt, \& Rössler, 2003), Australia (Jorm et al., 1997), Germany (Matschinger \& Angermeyer, 1996), Great Britain (e.g., Furnham \& Kuyken, 1991), Ireland (McKeon \& Carrick, 1991), and Turkey (Cirakoglu, Kokdemir, \& Demirutku, 2003), laypersons have consistently endorsed psychosocial over biochemical factors as likely causes of depression. We would note here that such views may change over time (though this is unclear) to the extent that DTC advertising encroaches into areas where it is now ostensibly banned. For example, some DTC advertising is now seen in European Union countries via satellite broadcasts as well as the Internet (Sullivan, 2000). In Canada, Food and Drug Act interpretations have softened such that reminder and helpseeking ads are commonplace (Gardner et al., 2003); as well, many product-claim ads originating in the United States leak into Canada across their shared border.

The study described next explored how one group of U.S. laypersons currently view and interpret chemical imbalance explanations of depression. We note here that our study did not assess individual personality and cognitive differences that might influence etiological beliefs. For example, a pessimistic explanatory style consisting of relatively internal, stable, and global attributions for negative events is a risk factor for depression (Peterson, Buchanan, \& Seligman, 1995), can remain relatively consistent over time, and might influence one's etiological views of depression. As such, we suggest future studies linking the large literature on attributions in depression (e.g., Abramson, Metalsky, \& Alloy, 1989) to the topics of this article.

\section{The Survey}

Participants in this study completed a survey. Copies of the survey are available from Christopher M. France. Participants were adult students drawn from several undergraduate psychology classes at a Midwestern university. A wide variety of majors was represented. Of the 433 students on the class rosters, $262(60.5 \%)$ participated in the study. The institutional review board of the university approved the study. Participants were informed of the general purpose of the study and assured of anonymity; in turn, they provided informed, written consent to participate. A vignette of an adult male or female suffering from (unipolar) major depression was included in the survey. Christopher M. France presented the survey in classroom settings, providing each participant with a written copy of the survey and reading each item aloud. We selected and maintained an alpha level of .05 across all inferential tests.

\section{Demographic Data}

The survey was completed by 262 participants: $156(59.5 \%)$ were female, $102(38.9 \%)$ were male, and 4 did not note their gender. Average age of participants was 23.6 years $(S D=7.23)$, with a range from 18 to 58 years. Average full years of education completed was 13.17 ( $S D=1.29)$; however, our measure underestimated educational level (details are available from Christopher M. France). A total of 155 (59.2\%) participants were White, 65 (24.8\%) were African American, and the remaining (16\%) identified as of other or mixed ethnicity or did not answer the item. We asked about annual household income as a measure of socioeconomic status (SES): 73 (27.9\%) participants lived in lower income households (\$24,999 or less), $138(52.7 \%)$ lived in middle income households $(\$ 25,000-\$ 74,999)$, and $51(19.5 \%)$ lived in upper income households $(\$ 75,000$ or above). Fifty respondents $(19.1 \%)$ reported a history of being diagnosed with and/or seeking treatment for depression; rates were higher for women (about 20.6\%) than men (about 15.7\%). Such rates of formal diagnosis/treatment seeking are higher than expected (e.g., see Kessler et al., 2003, regarding treatment rates); however, the meaning of this finding is obscured because of a lack of clear operational definitions for the elements of the relevant survey item.

\section{Spontaneously Generated Causes of Depression}

Following presentation of a depression vignette, participants generated up to five likely causes of depression and then rankordered the causes from most likely to least likely to cause depression. A total of 251 participants provided usable responses. We generated a list of the top-ranked causes of depression, and Christopher M. France and Paul H. Lysaker independently organized these raw data into meaningful, related categories. The separate lists were compared and discussed until agreement was reached as to the number and types of categories to use to best organize the responses. A random sample of 40 surveys was then selected (using a random numbers table), and Christopher $\mathrm{M}$. France and Paul H. Lysaker separately placed the responses into 
the agreed-upon categories. A comparison of results suggested good interrater reliability: 39 of $40(97.5 \%)$ responses were categorized in the same way by both authors (Cohen's kappa $=.97$ ).

As shown in Table 1, participants most often cited chemical imbalance as the single most likely cause of depression. However, note that chemical imbalance was cited as the most likely cause of depression by a minority of respondents (16.3\%), with most of the remaining (top-ranked) responses suggesting nonbiological causes of depression. This finding suggests the respondents viewed depression as potentially having multiple causes, with chemical imbalance being an important biological, but certainly not the only, potential cause of depression.

\section{Exposure to the Chemical Imbalance Explanation for Depression}

Participants were asked if they had previously seen or heard depression described as being caused by a "chemical imbalance" or "imbalance of chemicals in the brain." A total of $240(91.6 \%)$ respondents answered "yes" to the question, and $22(8.4 \%)$ answered "no." The "yes" responders were then asked where and how they had seen or heard depression described in this manner. As shown in Table 2, participants most often reported receiving the chemical imbalance explanation via television $(88.6 \%, n=210)$, followed by family, friends, or other acquaintances.

\section{Likely Cause of Depression (Likert-Type Items)}

Participants were presented with Likert-scaled questions, randomized as to order, concerning seven possible causes of depression. Wording was as follows: "How likely is it that depression might be caused by (potential cause)?" Responses ranged from 1 (very unlikely) to 5 (very likely). As seen in Table 3, many respondents $(84.7 \%, n=222)$ viewed chemical imbalance as a potential cause of depression. However, certain psychosocial stressors were endorsed even more frequently than chemical imbalance as potential causes of depression. Our sample thus again viewed chemical imbalance as a primary biological, but clearly not the only, potential cause of depression.

Table 1

Spontaneously Generated Possible Causes of Depression (TopRanked Choices)

\begin{tabular}{lcc}
\hline \multicolumn{1}{c}{ Top-ranked cause of depression } & No. of times cited & $\%$ \\
\hline Chemical imbalance & 41 & 16.3 \\
Death of family member/loved one & 37 & 14.7 \\
Relationship problems & 34 & 13.5 \\
Money/job problems & 33 & 13.1 \\
Stress & 31 & 12.4 \\
Low self-esteem & 28 & 11.2 \\
Trauma/abuse/other loss & 12 & 4.8 \\
Heredity/genetic & 6 & 2.4 \\
Failure to reach goals & 4 & 1.6 \\
Other ( $\leq 3$ instances each per category) & 25 & $10.0^{\mathrm{a}}$ \\
\hline
\end{tabular}

Note. There were 251 valid responses to this item.

${ }^{\text {a }}$ Combined.
Table 2

Exposure to the Chemical Imbalance Explanation for Depression

\begin{tabular}{|c|c|c|c|c|}
\hline \multirow[b]{2}{*}{ Seen or heard via the following: } & \multicolumn{2}{|c|}{ Yes } & \multicolumn{2}{|c|}{ No } \\
\hline & $n$ & $\%$ & $n$ & $\%$ \\
\hline Television & 210 & 88.6 & 27 & 11.4 \\
\hline $\begin{array}{l}\text { Friend/family member/other } \\
\text { acquaintance }\end{array}$ & 161 & 67.9 & 76 & 32.1 \\
\hline Magazines & 152 & 64.1 & 85 & 35.9 \\
\hline Books & 121 & 51.1 & 116 & 48.9 \\
\hline Physician or other medical professional & 109 & 46.0 & 128 & 54.0 \\
\hline Psychologist/mental health professional & 105 & 44.3 & 132 & 55.7 \\
\hline Radio & 88 & 37.1 & 149 & 62.9 \\
\hline Newspapers & 73 & 30.8 & 164 & 69.2 \\
\hline
\end{tabular}

Note. This item was completed only by those 240 participants $(n=237$ valid responses) who reported previously seeing or hearing depression described as resulting from a chemical imbalance. Categories are not mutually exclusive.

\section{Endorsement and Understanding of the Chemical Imbalance Metaphor}

We used five Likert-scaled items (see Table 4 for exact wording) to assess (a) participants' endorsement of chemical imbalance as the primary cause of depression and (b) their understanding of how brain chemicals might be used by doctors to diagnose and treat depression. Response choices ranged from 1 (strongly disagree) to 5 (strongly agree).

As shown in Table 4, over half (54.2\%) of the sample agreed that depression is primarily caused by a chemical imbalance. As this finding conflicts with those reported in Table 1, it appears possible that the item's wording primed or biased respondents toward endorsement. A minority but not inconsequential percentage of respondents also endorsed beliefs (Items 3 and 4 of Table 4) that doctors can measure brain chemicals to determine the presence $(24 \%, n=63)$ and severity $(22.1 \%, n=58)$ of depression.

To assess whether demographic and personal variables might have influenced responses to Table 4 items, we first developed a measure of the degree to which each participant believed doctors understand, measure, and manipulate brain chemicals during depression diagnosis and treatment. This measure (scale score) consisted of the average of responses to Items 2-5 of Table 4 . As each item is on a 5-point ( 1 to 5) scale, the mean scale score was also between 1 and 5 for each participant. Coefficient alpha for the scale was .66.

We then performed a $2 \times 3 \times 2 \times 2$ analysis of variance (ANOVA) using gender, SES (low, middle, high), past depression diagnosis/treatment seeking (yes/no), and ethnicity (limited to African American or White status; $n=220$ of 262 total participants) as the independent variables and scale score as described above as the dependent variable. The four-way interaction term was not significant, but the three-way interaction between gender, SES, and past depression diagnosis/treatment seeking was significant, $F(2,194)=3.39, p<.05$. In order to interpret this three-way interaction, we performed separate $2 \times 2$ ANOVAs using gender and past diagnosis/treatment seeking status for each of the three SES levels.

Results indicated a significant $2 \times 2$ interaction effect between gender and past diagnosis/treatment seeking for the middle SES 
Table 3

How Likely Is It That Depression Might Be Caused by the Following?

\begin{tabular}{|c|c|c|c|c|c|c|}
\hline \multirow[b]{2}{*}{ Potential cause } & \multicolumn{2}{|c|}{ Likely } & \multicolumn{2}{|c|}{ Undecided } & \multicolumn{2}{|c|}{ Unlikely } \\
\hline & $n$ & $\%$ & $n$ & $\%$ & $n$ & $\%$ \\
\hline Recent or ongoing stressful circumstances & 257 & 98.1 & 1 & 0.4 & 4 & 1.5 \\
\hline Difficult childhood experiences & 224 & 85.5 & 24 & 9.2 & 14 & 5.3 \\
\hline Chemical imbalance & 222 & 84.7 & 29 & 11.1 & 11 & 4.2 \\
\hline Excess drug/alcohol use & 207 & 79.0 & 32 & 12.2 & 23 & 8.8 \\
\hline Genetic/inherited problem & 162 & 61.8 & 38 & 14.5 & 62 & 23.7 \\
\hline One's own bad character & 143 & 54.6 & 53 & 20.2 & 66 & 25.2 \\
\hline Virus/infection & 70 & 26.7 & 58 & 22.1 & 134 & 51.1 \\
\hline
\end{tabular}

Note. Responses were on a 5-point scale ranging from 1 (very unlikely) to 5 (very likely) and are collapsed into the three categories above for reporting purposes.

group (\$25,000-\$74,999 annual household income) only, $F(1$, $194)=3.70, p<.05$. In order to interpret the interaction effect, we performed univariate ANOVAs for each gender. Results indicated a significant main effect for past diagnosis/treatment seeking, $F(1$, $194)=4.97, p<.05$, such that medium SES women who had not been previously diagnosed with or sought depression treatment were more likely (mean scale score $=3.18$ ) to believe that doctors understand, measure, and manipulate brain chemicals during depression diagnosis and treatment than middle SES women who had been previously diagnosed with or sought treatment for depression $(M=2.72)$. This effect was not found for men, $F(1,194)=.80, n s$.

\section{Treatment-Seeking Strategies and Endorsement of the Chemical Imbalance Explanation}

Participants were also asked whom they would contact first if seeking professional help for depression, and 260 provided usable responses. A total of $115(44.2 \%)$ respondents reported they would contact their family physician; 88 (33.8\%) reported they would contact a psychologist, counselor, or other psychotherapist; 29 $(11.2 \%)$ reported they would contact a religious advisor (e.g., pastor, priest, rabbi, and so forth); and 28 (10.8\%) reported they would contact a psychiatrist. We conducted a one-way ANOVA to determine whether such treatment preferences (four groups) were related to levels of endorsement of chemical imbalance as the primary cause of depression (Item 1 in Table 4). Results indicated significant differences among the groups, $F(3,265)=4.19, p<$ .05. Tukey's post hoc comparisons revealed those who would initially seek depression treatment from a medical doctor also endorsed chemical imbalance as the primary cause of depression at higher levels ( $M=3.75$ for family physician group; $M=3.56$ for psychiatrist group; $p<.05$ for all comparisons) than those who would seek initial treatment from a psychologist/counselor $(M=$ $3.35)$ or religious advisor $(M=3.17)$.

\section{Summary and Implications}

The monoamine hypothesis has provided the impetus for numerous important research projects seeking the biological causes of depression and efficacious pharmacological treatments for the same. However, this chemical imbalance explanation remains unproven and is potentially invalid. The significant limitations of the imbalance explanation, however, have not prevented U.S. laypersons (as well as some treating professionals and other stakeholders) from being urged (e.g., via DTC advertisements) to accept the explanation as a likely fact.

The convenience sample used in this study reported widespread exposure to the chemical imbalance explanation for depression, most often via television, and many in the sample viewed chemical imbalance as a potential or even primary cause of depression. A

Table 4

Endorsement and Understanding of the Chemical Imbalance Explanation for Depression

\begin{tabular}{|c|c|c|c|c|c|c|}
\hline \multirow[b]{2}{*}{ Statement } & \multicolumn{2}{|c|}{ Agree } & \multicolumn{2}{|c|}{ Undecided } & \multicolumn{2}{|c|}{ Disagree } \\
\hline & $n$ & $\%$ & $n$ & $\%$ & $n$ & $\%$ \\
\hline $\begin{array}{l}\text { 1. Depression is primarily caused by an imbalance of } \\
\text { chemicals in the brain. }\end{array}$ & 142 & 54.2 & 76 & 29.0 & 44 & 16.8 \\
\hline $\begin{array}{l}\text { 2. Doctors understand which specific brain chemicals } \\
\text { are involved in causing depression. }\end{array}$ & 118 & 45.0 & 112 & 42.8 & 32 & 12.2 \\
\hline $\begin{array}{l}\text { 3. Doctors can measure levels of brain chemicals to } \\
\text { tell who is depressed and who is not depressed. }\end{array}$ & 63 & 24.0 & 114 & 43.5 & 85 & 32.4 \\
\hline $\begin{array}{l}\text { 4. Doctors are able to measure chemicals in the brain } \\
\text { to determine one's level of depression. }\end{array}$ & 58 & 22.1 & 117 & 44.7 & 87 & 33.2 \\
\hline $\begin{array}{l}\text { 5. Doctors can fix depression by adding or subtracting } \\
\text { brain chemicals until properly balanced. }\end{array}$ & 92 & 35.1 & 87 & 33.2 & 83 & 31.7 \\
\hline
\end{tabular}

Note. Responses were on a 5-point scale ranging from 1 (strongly disagree) to 5 (strongly agree) and are collapsed into the three categories above for reporting purposes only. 
minority but not inconsequential number of respondents reported beliefs that doctors understand the chemical bases of depression and use objective chemical measures to quantify depression and guide its treatment. To the extent that such beliefs are inaccurate, they may limit one's understanding of treatment options and/or leave one with overly high expectations of treatment success.

Interesting clinical questions are raised to the extent that the beliefs of your depressed clients mirror those of some in our sample. For example, how much information should be provided to clients concerning the validity (or potential lack thereof) of chemical imbalance explanations for depression? Is it unethical to gloss over the complexities of this and related (e.g., antidepressant vs. placebo efficacy) issues? What about the client who has been referred for adjunctive psychotherapy but does not see such treatment as important because she or he expects medication to resolve her or his depression? Alternately, how should you approach a discouraged patient who had assumed that his or her chemical imbalance would respond (but has not responded) to the antidepressant seen on television?

The beliefs of other professionals and stakeholders concerning chemical imbalance explanations also have the potential to impact your practice of psychology. For example, if you work as part of a team involving medical staff, will views diverging from a chemical imbalance model of depression clash with those adhering to a purer medical model? If so, how might such differences affect a particular client's treatment, your relationship with that client, your relationships with coworkers, and even potential referrals? Will clients who make an informed decision to eschew medication be viewed (e.g., by treatment staff, family members, and so forth) as "resistant" to treatment and unwilling to "get well"? Will a client's insurance company direct the client to pharmacological treatments but avoid paying for the psychotherapy that might be equally efficacious as well as offering the advantage of no troublesome side effects?

It is likely that many clinicians have faced (or if in training, will face in the future) at least some of the situations noted above. Fortunately, professional psychologists have the skills to critically evaluate findings related to chemical imbalances in depression, to reach reasonably accurate conclusions to various related etiological and treatment questions, and to pass such conclusions on to consumers (and other professionals when necessary) in a helpful manner. A relatively straightforward script that might be of use when attempting to educate clients (or other interested parties) as to chemical imbalances in depression and its treatment might include the following points:

- Chemical imbalance hypotheses of depression causation have been quite useful in many ways (e.g., by stimulating research and influencing the development of new antidepressants). However, at present such hypotheses remain unproven and, at least as presented in many television ads, are likely overly simplistic and oversold.

- There are potentially many different causes of depression. We do not know with certainty how or to what degree biology (including monoamine deficiencies) might cause depression.

- Currently, depression is not diagnosed via objective chemical tests, nor is treatment guided by any such tests. If depression did result primarily from a known chemical imbalance, such tests would likely be available and in widespread use, and depression would be easily and quickly resolved for most patients.
- Luckily, a number of effective interventions are available for treating depression. Such interventions include a variety of pharmacological as well as nonpharmacological approaches, sometimes used alone and sometimes in combination with one another.

Before closing, we wish to reiterate that our survey data were derived from a convenience sample and as such cannot be confidently generalized to U.S. adults as a whole. Limitations of our survey also included potential item wording and self-selection biases and a primary reliance on response types (i.e., Likert and categorical responses), which resulted in data that are perhaps somewhat artificial. We recommend future studies in this area attempt to avoid such limitations. Future studies could also be expanded to include questions such as these: How do some laypersons come to believe that biochemical measures of depression are widely used? Does personal endorsement of the chemical imbalance explanation affect how one responds to others who come to them for advice regarding depression treatment? How does one's explanatory style for negative events influence etiological beliefs concerning depression? Are persons who endorse the imbalance explanation for depression more likely to offer social support to depressed persons? What beliefs do different professionals (e.g., nurses vs. counselors) hold concerning imbalance theories of depression? In closing, future studies might also examine changes over time, both in and outside the United States, of lay endorsement of chemical imbalance explanations.

\section{References}

Abramson, L. Y., Metalsky, G. I., \& Alloy, L. B. (1989). Hopelessness depression: A theory-based subtype of depression. Psychological Review, 96, 358-372.

Antonuccio, D. O., Danton, W. G., DeNelsky, G. Y., Greenberg, R. P., \& Gordon, J. S. (1999). Raising questions about antidepressants. Psychotherapy and Psychosomatics, 68, 3-14.

Antonuccio, D. O., Danton, W. G., \& McClanahan, T. M. (2003). Psychology in the prescription era: Building a firewall between marketing and science. American Psychologist, 58, 1028-1043.

Asberg, M., Bertilsson, L., Martensson, B., Scalia-Tomba, G. P., Thoren, P., \& Traskman-Bendz, L. (1984). CSF monoamine metabolites in melancholia. Acta Psychiatrica Scandinavica, 69, 201-219.

Asberg, M., Thoren, P., Traskman, L., Bertilsson, L., \& Ringberger, V. (1976). Serotonin depression: A biological subgroup within the affective disorders? Science, 191, 478-480.

Babyak, M., Blumenthal, J. A., Herman, S., Khatri, P., Doraiswamy, M., Moore, K., et al. (2000). Exercise treatment for major depression: Maintenance of therapeutic benefit at 10 months. Psychosomatic Medicine, 62, 633-638.

Barsa, J. A., \& Kline, N. S. (1956). Use of reserpine in disturbed psychotic patients. American Journal of Psychiatry, 112, 684-691.

Baumeister, A. A., Hawkins, M. F., \& Uzelac, S. M. (2003). The myth of reserpine-induced depression: Role in the historical development of the monoamine hypothesis. Journal of the History of the Neurosciences, 12, 207-220.

Benkelfat, C., Ellenbogen, M. A., Dean, P., Palmour, R. M., \& Young, S. M. (1994). Mood-lowering effect of tryptophan depletion: Enhanced susceptibility in young men at genetic risk for major affective disorders. Archives of General Psychiatry, 51, 687-697.

Berman, R., Narasimhan, M., Miller, H. L., Anand, A., Cappiello, A., Oren, D. A., et al. (1999). Transient depressive relapse induced by catecholamine depletion: Potential phenotypic vulnerability marker? Archives of General Psychiatry, 56, 395-403. 
Bianchi, M., Moser, C., Lazzarini, C., Vecchiato, E., \& Crespi, F. (2002). Forced swimming test and fluoxetine treatment: In vivo evidence that peripheral 5-HT in rat platelet-rich plasma mirrors cerebral extracellular 5-HT levels, whilst 5-HT in isolated platelets mirrors neuronal 5-HT changes. Experimental Brain Research, 143, 191-197.

Bogdanski, D. F., Weissbach, H., \& Udenfriend, S. (1958). Pharmacological studies with the serotonin precursor, 5-hydroxytryptophan. Journal of Pharmacology and Experimental Therapeutics, 122, 182-194.

Booij, L., Van der Does, W., Benkelfat, C., Bremner, J. D., Cowen, P. J., Fava, M., et al. (2002). Predictors of mood response to acute tryptophan depletion: A reanalysis. Neuropsychopharmacology, 27, 852-861.

Brodie, B. B., \& Shore, P. A. (1957). A concept for the role of serotonin and norepinephrine as chemical mediators in the brain. Annals of the New York Academy of Sciences, 66, 631-642.

Cirakoglu, O. C., Kokdemir, D., \& Demirutku, K. (2003). Lay theories of causes and cures for depression in a Turkish university sample. Social Behavior and Personality, 31, 795-806.

Cook, I. A., Leuchter, A. F., Morgan, M. L., Stubbeman, W., Siegman, B., \& Abrams, M. (2005). Changes in prefrontal activity characterize clinical response in SSRI nonresponders: A pilot study. Journal of Psychiatric Research, 39, 461-466.

Coppen, A. (1967). The biochemistry of affective disorders. British Journal of Psychiatry, 113, 1237-1264.

Crane, G. E. (1957). Iproniazid (Marsilid ${ }^{\circledR}$ ) phosphate, a therapeutic agent for mental disorders and debilitating diseases. Psychiatric Research Reports, 8, 142-152.

Delgado, P. L. (2000). Depression: The case for a monoamine deficiency. Journal of Clinical Psychiatry, 61(Suppl. 6), 7-11.

Delgado, P. L. (2004). How antidepressants help depression: Mechanisms of action and clinical response. Journal of Clinical Psychiatry, 65(Suppl. 4), 25-30.

Delgado, P. L., Charney, D. S., Price, L. H., Aghajanian, G. K., Landis, H., \& Heninger, G. R. (1990). Serotonin function and the mechanism of antidepressant action. Reversal of antidepressant-induced remission by rapid depletion of plasma tryptophan. Archives of General Psychiatry, 47, 411-418.

Delgado, P. L., Miller, H. L., Salomon, R. M., Licinio, J., Heninger, G. R., Gelenberg, A. J., et al. (1993). Monoamines and the mechanism of antidepressant action: Effects of catecholamine depletion on mood of patients treated with antidepressants. Psychopharmacology Bulletin, 29, 389-396.

Delgado, P. L., Miller, H. L., Salomon, R. M., Licinio, J., Krystal, J. H., Moreno, F. A., et al. (1999). Tryptophan-depletion challenge in depressed patients treated with desipramine or fluoxetine: Implications for the role of serotonin in the mechanism of antidepressant action. Biological Psychiatry, 46, 212-220.

Delgado, P. L., \& Moreno, F. (1999). Antidepressants and the brain. International Clinical Psychopharmacology, 14(Suppl. 1), S9-16.

Furnham, A., \& Kuyken, W. (1991). Lay theories of depression. Journal of Social Behavior \& Personality, 6, 329-342.

Gardner, D. M., Mintzes, B., \& Ostry, A. (2003). Direct-to-consumer prescription drug advertising in Canada: Permission by default? Canadian Medical Association Journal, 169, 425-427.

Gjerris, A. (1988). Baseline studies on transmitter substances in cerebrospinal fluid in depression. Acta Psychiatrica Scandinavica, 78(Suppl.), $1-35$.

Glowinski, J., \& Axelrod, J. (1964). Inhibition of uptake of tritiatednoradrenaline in the intact rat brain by imipramine and structurally related compounds. Nature, 204, 1318-1319.

Grow, J. M., Park, J. S., \& Han, Z. (2006). "Your life is waiting!” Symbolic meanings in direct-to-consumer antidepressant advertising. Journal of Communication Inquiry, 30, 163-188.

Healy, D. (1997). The antidepressant era. Cambridge, MA: Harvard University Press.
Healy, D. (2001). The antidepressant drama. In M. N. Weissman (Ed.), Treatment of depression: Bridging the $21^{\text {st }}$ century (pp. 7-34). Washington, DC: American Psychiatric Press.

Hindmarch, I. (2001). Expanding the horizons of depression: Beyond the monoamine hypothesis. Human Psychopharmacology: Clinical and Experimental, 16, 203-218.

Hindmarch, I. (2002). Beyond the monoamine hypothesis: Mechanisms, molecules and methods. European Psychiatry, 17(Suppl. 3), 294-299.

Hirschfeld, R. (2000). History and evolution of the monoamine hypothesis of depression. Journal of Clinical Psychiatry, 61(Suppl. 6), 4-6.

Jorm, A. F., Korten, A. E., Jacomb, P. A., Christensen, H., Rodgers, B., \& Pollitt, P. (1997). Public beliefs about causes and risk factors for depression and schizophrenia. Social Psychiatry and Psychiatric Epidemiology, 32, 143-148.

Kessler, R. C., Berglund, P., Demler, O., Jin, R., Koretz, D., Merikangas, K. R., et al. (2003). The epidemiology of major depressive disorder: Results from the National Comorbidity Survey Replication (NCS-R). Journal of the American Medical Association, 289, 3095-3105.

Kirsch, I., Moore, T. J., Scoboria, A., \& Nicholls, S. S. (2002). The emperor's new drugs: An analysis of antidepressant medication data submitted to the U.S. Food and Drug Administration. Prevention and Treatment, 5, Article 00232a. Retrieved June 29, 2004, from http:// journals.apa.org/prevention/volume5/pre0050023a.html

Kirsch, I., Scoboria, A., \& Moore, T. J. (2002). Antidepressants and placebos: Secrets, revelations, and unanswered questions. Prevention and Treatment, 5, Article 33. Retrieved June 29, 2004, from http:// journals.apa.org/prevention/volume5/toc-jul15-02.htm

Klaassen, T., Riedel, W. J., van Someren, A., Deutz, N. E., Honig, A., van Praag, H. M., et al. (1999). Mood effects of 24-hour tryptophan depletion in healthy first-degree relatives of patients with affective disorders. Biological Psychiatry, 46, 489-497.

Kravitz, R. L., Epstein, R. M., Feldman, M. D., Franz, C. E., Azari, R., Wilkes, M. S., et al. (2005). Influence of patients' requests for directto-consumer advertised antidepressants: A randomized controlled trial. Journal of the American Medical Association, 293, 1995-2002.

Kuhn, R. (1958). The treatment of depressive states with G22355 (imipramine hydrochloride). American Journal of Psychiatry, 115, 459464.

Lauber, C., Falcato, L., Nordt, C., \& Rössler, W. (2003). Lay beliefs about causes of depression. Acta Psychiatrica Scandinavica, 108(Suppl. 418), 96-99.

Leonard, B. E. (2000). Evidence for a biochemical lesion in depression. Journal of Clinical Psychiatry, 61(Suppl. 6), 12-17.

Lilly. (2006). How Prozac can help: How it works. Retrieved May 25, 2006, from http://www.prozac.com/how_prozac/how_it_works .jsp?reqNavId=2.2.

Link, B. G., Phelan, J. C., Bresnahan, M., Stueve, A., \& Pescosolido, B. A. (1999). Public conceptions of mental illness: Labels, causes, dangerousness, and social distance. American Journal of Public Health, 89, 1328 1333.

Loomer, H. P., Saunders, J. C., \& Kline, N. S. (1957). A clinical and pharmacodynamic evaluation of iproniazid as a psychic energizer. Psychiatric Research Reports, 8, 129-141.

Marsella, A. J., \& Kaplan, A. (2002). Cultural considerations for understanding, assessing, and treating depressive experience and disorders. In M. A. Reinecke \& M. R. Davidson (Eds.), Comparative treatments of depression (pp. 47-78). New York: Springer.

Masand, P. S., \& Gupta, S. (1999). Selective serotonin-reuptake inhibitors: An update. Harvard Review of Psychiatry, 7, 69-84.

Matschinger, H., \& Angermeyer, M. C. (1996). Lay beliefs about the causes of mental disorders: A new methodological approach. Social Psychiatry and Psychiatric Epidemiology, 31, 309-315.

McEwen, B. S. (1999). Stress and hippocampal plasticity. Annual Review of Neuroscience, 22, 105-122. 
McKeon, P., \& Carrick, S. (1991). Public attitudes to depression: A national survey. Irish Journal of Psychological Medicine, 8, 116-121.

Miller, H. L., Delgado, P. L., Salomon, R. M., Berman, R., Krystal, J. H., Heninger, G. R., et al. (1996). Clinical and biochemical effects of catecholamine depletion on antidepressant-induced remission of depression. Archives of General Psychiatry, 53, 117-128.

Miller, H. L., Delgado, P. L., Salomon, R. M., Heninger, G. R., \& Charney, D. S. (1996). Effects of alpha-methyl-para-tyrosine (AMPT) in drug-free depressed patients. Neuropsychopharmacology, 14, 151-158.

National Institute for Health Care Management Research and Educational Foundation. (2002, May 6). Prescription drug expenditures in 2001: Another year of escalating costs. Retrieved May 25, 2006, from http:// www.nihcm.org/spending2001.pdf

Neumeister, A., Nugent, A. C., Waldeck, T., Geraci, M., Schwarz, M., Bonne, O., et al. (2004). Neural and behavioral responses to tryptophan depletion in unmedicated patients with remitted major depressive disorder and controls. Archives of General Psychiatry, 61, 765-773.

Owens, M. J. (2004). Selectivity of antidepressants: From the monoamine hypothesis of depression to the SSRI revolution and beyond. Journal of Clinical Psychiatry, 65(Suppl. 4), 5-10.

Palumbo, F. B., \& Mullins, C. D. (2002). The development of direct-toconsumer prescription drug advertising regulation. Food and Drug Law Journal, 57, 423-443.

Peterson, C., Buchanan, G. M., \& Seligman, M. E. P. (1995). Explanatory style: History and evolution of the field. In G. M. Buchanan \& M. E. P. Seligman (Eds.), Explanatory style (pp. 1-20). Hillsdale, NJ: Erlbaum.

Pletscher, A. (1991). The discovery of antidepressants: A winding path. Experientia, 47, 4-8.

Rothman, D. J. (1971). The discovery of the asylum: Social order and disorder in the new republic. Boston: Little, Brown.

Salomon, R. M., Miller, H. L., Delgado, P. L., \& Charney, D. (1993). The use of tryptophan depletion to evaluate central serotonin function in depression and other neuropsychiatric disorders. International Clinical Psychopharmacology, 8(Suppl. 2), 41-46.

Salomon, R. M., Miller, H. L., Krystal, J. H., Heninger, G. R., \& Charney, D. S. (1997). Lack of behavioral effects of monoamine depletion in healthy subjects. Biological Psychiatry, 41, 58-64.

Schildkraut, J. J. (1965). The catecholamine hypothesis of affective disorders: A review of supporting evidence. American Journal of Psychiatry 122, 509-522.

Sedvall, G., Fyro, B., Gullberg, B., Nyback, H., Wiesel, F., \& WodeHelgodt, B. (1980). Relationships in healthy volunteers between concentrations of monoamine metabolites in cerebrospinal fluid and family history of psychiatric morbidity. British Journal of Psychiatry, 136, 366-374.

Sheline, Y. I. (2003). Neuroimaging studies of mood disorder effects on the brain. Biological Psychiatry, 54, 338-352.

Shore, P. A., Silver, S. L., \& Brodie, B. B. (1955). Interaction of reserpine, serotonin, and lysergic acid diethylamide in brain. Science, 12, 284-285.

Smith, D. C. (1999). Commentary: The limits of biological psychiatry. Journal of the American Academy of Psychoanalysis and Dynamic Psychiatry, 27, 671-680.

Sullivan, R. (2000). Direct-to-consumer advertising: The future in Europe Journal of the Royal Society of Medicine, 93, 400-401.

Valenstein, E. S. (1998). Blaming the brain. New York: The Free Press.

Wagstaff, A. J., Ormrod, D., \& Spencer, C. M. (2001). Tianeptine: A review of its use in depressive disorders. CNS Drugs, 15, 231-259.

Received February 15, 2006

Revision received June 5, 2006

Accepted June 30, 2006

\section{E-Mail Notification of Your Latest Issue Online!}

Would you like to know when the next issue of your favorite APA journal will be available online? This service is now available to you. Sign up at http://watson.apa.org/ notify/and you will be notified by e-mail when issues of interest to you become available! 